\title{
Germicidal Action of Some Metals/Metal Ions in Combating E. coli Bacteria in Relation to Their Electro-Chemical Properties
}

\author{
Alakaparampil Joseph Varkey ${ }^{1}$, Mgidi Donald Dlamini ${ }^{1}$, Anaclet Bwampamye Mansuetus ${ }^{2}$, \\ Ababu Teklemariam Tiruneh ${ }^{3}$ \\ ${ }^{1}$ Department of Physics, University of Swaziland, Kwaluseni, Swaziland \\ ${ }^{2}$ Department of Biological Sciences, University of Swaziland, Kwaluseni, Swaziland \\ ${ }^{3}$ Department of Environmental Health Science, University of Swaziland, Mbabane, Swaziland \\ Email: varkey@uniswa.sz,mgidi@uniswa.sz,mansuetus@uniswa.sz, atiruneh@uniswa.sz
}

Received August 18, 2013; revised September 23, 2013; accepted October 21, 2013

Copyright (C) 2013 Alakaparampil Joseph Varkey et al. This is an open access article distributed under the Creative Commons Attribution License, which permits unrestricted use, distribution, and reproduction in any medium, provided the original work is properly cited.

\begin{abstract}
The germicidal properties of some metals and metal compounds were investigated in relation to their electro-chemical properties that may play a role in the inactivation of $E$. coli bacteria. These properties included the atomic and ionic radii, ionization energy, oxidation state, energy of formation with hydro-sulfide groups, and the redox potential of the metals. Cultures of E. coli bacteria with predetermined numbers of colony-forming units (CFU's) were brought in contact with the metals as well as metal compounds, using Eosin methylene blue agar medium and sterilized, distilled water. The rate of inactivation was determined by counting the CFU's at predefined intervals of time after inoculation. The experimental results showed that the rate of inactivation increases with increasing ionization energy of the metals. While the rate of inactivation increases with decreasing atomic radii for some of the transition metals, there is no apparent relationship between ionic radius and rate of inactivation for the metal compounds. In addition, non-transition group III metals such as aluminum and indium showed higher rates of inactivation that are comparable to the action of silver. This is probably due to the increase in coagulation potential and the resulting adsorption of bacteria, because a larger number of ions are able electrons carried by these atoms. In general, there is a difference between the atoms and the ions in terms of their rate of inactivation. This difference increases amongst the transition metals that have lower oxidation potential, lower ionization potential as well as larger ionic radius. The results also showed that for the metals, adsorption through coagulation is an important fact or that is responsible for inactivation of $E$. coli. For the metal compounds, additional mechanisms such as direct reaction through complex formation, physico-chemical distortion of the cell structure through direct entry of the ions into the cell, may contribute towards greater inactivation.
\end{abstract}

Keywords: Metal Inactivation; Disinfection; Heavy Metal Toxicity; Water Treatment; Rate of Inactivation; Escherichia coli

\section{Introduction}

Heavy metals are roughly delineated with a mass density higher than $5 \mathrm{~g} / \mathrm{cm}^{3}$. Out of the 90 elements found in nature, 53 are heavy metals, constituting over $50 \%$ in abundance [1]. By and large, the heavy metals belong to the transition elements within complete d-orbital electrons. They can easily lose electrons from the transition orbital and form cations that have the ability to form complex compounds with a reduction-oxidation potential $[2,3]$. Several of the heavy metals are important to biological life. Among the 17 heavy metals that are useful to organ- isms and the ecosystems, $\mathrm{Fe}$, Mo and $\mathrm{Mn}$ are needed as micronutrients [1]. On the other hand, $\mathrm{Zn}, \mathrm{Ni}, \mathrm{Cu}, \mathrm{V}, \mathrm{Co}$, $\mathrm{W}$, and $\mathrm{Cr}$ do have importance as trace elements. However, they are toxic at high concentrations. The elements $\mathrm{As}, \mathrm{Hg}, \mathrm{Ag}, \mathrm{Sb}, \mathrm{Cd}, \mathrm{Pb}$, and $\mathrm{U}$ do not have recognized importance to biological life. Their toxicity, however, has been reported $[2,4,5]$.

\subsection{Biocidal Properties of Heavy Metals}

Silver ions are known from the long past to have a strong biocidal effect against a wide range of pathogenic micro- 
organisms [6]. Copper has also been in wide use for medical, cleaning, preservative and many other useful purposes because of the low sensitivity of the human skin and tissue to copper compared to the high level of susceptibility of microorganisms. The application of copper for medicinal uses is quite ubiquitous [7]. However, copper, at high concentration, shows toxicity to fish whereas the level of toxicity of copper is greater in soft water than in hard water.

Other heavy metals such as zinc and nickel do not readily undergo redox cycling like copper which is believed to be responsible for its biocidal properties and is more stable in its cationic oxidation states $[8,9]$. Therefore, their use for medicinal application and as a biocide is limited. However, zinc, while being an essential micronutrient to humans similar to copper, shows biocidal properties against fungi [10]. Zinc pyrithione is used as an antifouling agent in paints [11]. Zinc solution at higher concentration is toxic to higher forms of life, including humans and its oxidative property at such concentration limits its applicability as a biocide [12].

Contemporary applications of heavy metal inactivation to disease causing viruses have been reported in medical applications. The oxidation of the tyrosine phosphatase in the cysteine of the Vaccinia $\mathrm{H} 1$ virus by copper ion led to complete inactivation of the protein function of the virus [13]. On the other hand, the HIV-1 protease which is useful for the replication of the virus has been neutralized through exposure to a proportional concentration of copper ions [14].

\subsection{Mechanism of Inactivation of Pathogens by Heavy Metals}

A number of previous research works revealed several mechanisms, by which the vital processes of the toxicity of heavy metals to the cells are expressed. These processes are discussed below.

1) Damage or destruction of the cell membrane:

The initial point of attack of heavy metals is understood to be the plasma membrane [15-17]. Exposure of microorganisms to higher concentrations of heavy metals leads to deterioration in membrane structure leading, in turn, to leakage of cellular solute materials such as potassium and eventual death of microorganisms. Oxidation of membrane lipids has also been reported to be the cause of cell damage in higher organisms [17-19]. Not all heavy metals are empowered, however, to cause damage through cell destruction at a given concentration. Chan et al. [20], for example, reported no significant effect by other transition metals than copper which, when used with $10 \mathrm{mM}$ of $\mathrm{H}_{2} \mathrm{O}_{2}$, catalyzed peroxidation of rat erythrocyte membrane lipid.

While extensive damage of the membrane integrity leads to an obvious loss of cell function, even a small change in the physico-chemical properties of cell membranes can result in considerable alteration in the functionalities of the several useful processes that are dependent on the integrity of the cell membrane and which, among others, includes the transport to protein activity [21], phagocytosis [22], and ion permeability [21].

The bactericidal properties of several pathogens (Streptococcus lactis, E. coli and P. aeruginosa), based on cell membrane loss of functionality, have been reported to be similar [23]. On the other hand, oxidation of susceptible compounds within the cell structure requires a more extensive degradation of cells, possibly at higher concentration.

2) Formation of oxidative stress environment within the cell structure.

The heavy metals in their ionic form (such as silver ion, copper ion, cadmium ion, etc.) display an affinity for binding with the so called sulfo hydroxyl group ( $\mathrm{SH}$ group) of the protein inside the cell [2]. For example, the heavy metal ions that are completed with glutathione, form a complex called bisglutathione. This complex further reacts with oxygen molecules and results in the formation of bisglutathionate, which is the oxidized form of bisglutathione. The formation of the oxidized forms, bisglutathionate, is accompanied by the release of the complexed metal ions and the formation of a reactive oxygen species (such as hydrogen peroxide). The metal ions, now freed from the complex, are able to react further in yet another cycle for the formation of additional bisglutathione and further oxidation [24,25].

3) Interference with vital functions of the cell.

The structure of a number of metal cation-based compounds displays resemblance with metabolically useful compounds. For example, chromate displays similarity with sulfate, whereas arsenate shows similarity with phosphate. This means that the metal forms mentioned can potentially interfere with the metabolic processes which will need the important compounds such as sulfate and phosphate [26].

4) Damage to DNA and protein through reduction of metals.

A number of metal ions are able to acquire a reduced state within the cell environment through processes involving the cell enzymes or through other processes. For example, chromium ion in the +6 oxidation state can be reduced to the +3 state. Likewise, copper can be reduced from the +2 oxidation state to the +1 state. The formation of reduced metal cations is accompanied by the release of reactive oxygen species which will oxidise and cause damage or destruction to several of the cell components that include the DNA and protein [27-29].

5) Displacement of Essential metals from their natural binding sites.

Heavy metals, in general, have greater affinity binding to the sulfohydroxyl groups than the essential metals. 
The complex formation with heavy metals as such occurs through displacement of the essential metals or through metal-ligand interaction.

\subsubsection{Destruction of the Cell Barrier}

The frontline attack of heavy metals begins with the cell membrane. Heavy metals such as copper have been observed attached to the plasma membrane of E. coli. Interestingly, steel that does not contain copper did not attach to the cell membrane, indicating a selective mechanism by which heavy metals are attracted towards the cell membrane [30]. The redox capability of heavy metals such as copper is observed as a factor in such selective binding.

The heavy metals that bind on the cell membranes cause damage to the lipopolysaccharide on the outer plasma membrane first. A significant alteration of the cell permeability follows, leading to loss of the vital function of the cell [16]. Cells rich with polyunsaturated fatty acids have been observed to lose much of the cell viability [31]. A slight change in the structural property of the cell membrane can induce a marked change in the activities of several useful cell functions that depend on membrane permeability barrier. These include the transport activities involving the proteins and the permeability of different ions [20].

\subsubsection{Mechanism of Transportation of Heavy Metals into the Cell Structure}

The entry of heavy metals into the bacterial cell is done through regulation involving the divalent cations or oxyanions [32]. However, heavy metals like other non-toxic metals are indistinguishably transported to the cytoplasm [2]. The heavy metals as such are not indistinguishable from the other divalent metal ions or oxyanions that are useful and pass across the membrane. These include $\mathrm{SO}_{4}^{2-}, \mathrm{HPO}_{4}^{2-}, \mathrm{Fe}^{2+}, \mathrm{Mg}^{2+}, \mathrm{Mn}^{2+}$, etc. Therefore, subject to a certain concentration, heavy metals are afforded direct entry into the cell across the cell membrane. However, toxicity effects result in a defense mechanism that forms a barrier to the entry of heavy metals. This phenomenon (metal resistance) will be discussed in a later section of this paper. X-ray examination of the cell structure has confirmed the existence of heavy metals such as silver occupying electro dense environments within the cell, caused by the entry of the heavy metals [33]. Most of the observed biocidal actions against the microorganisms, except those resulting from cell wall damage, can only take place if the heavy metals are able to enter the cell.

\subsubsection{Inactivation, Damage and Destruction of the Vital Contents of the Cell}

Once the heavy metals find their way into the cell struc- ture, they have an opportunity to form a complex reaction with the protein structure inside the cell. The thiol groups are known to be liable for the toxicity binding of heavy metals [34]. Metals, as such, cause inactivation of the protein inside the cells by reacting with the $\mathrm{SH}$ groups, belonging to the protein structure [35]. Experimental studies with silver, indicating reaction of silver with thiol groups, have been identified as critical for bacterial inactivation [36].

Reactive oxygen species such as $\mathrm{H}_{2} \mathrm{O}_{2}$ are further formed when oxygen reacts with metal-complexed $\mathrm{SH}$ groups [24]. The reactive oxygen species so formed cause oxidative stress within the cell, leading to inactivation of the vital functions of the cell. The synergistic action of oxidative stress and the metal complexed $\mathrm{SH}$ groups causes a diminishing level of the activity of the vulnerable enzymes [26].

A possible biocidal response of the stressed condition within the cell is physiological changes involving the DNA. The DNA is observed to shrink, leaving an electron sparse region in the cell while at the same time losing its ability to replicate when shrunk. A dense electron region is also formed towards the cell wall with a further potential of reaction involving the heavy metals surrounding the cell wall that can cause damage to the cell wall [32]. The change of the conformal structure of nucleic acid as well as cell proteins will result in loss of the vital cell function, including loss of osmotic balance.

While normal interaction of metals, such as copper, is possible with cell proteins of microorganisms, at elevated concentrations the heavy metals may damage the protein both on the outer cell membrane as well as inside $[37,38]$. Displacement of metals, interaction with the protein binding sites leading to conformal changes to the protein structure resulting in the inactivation of the protein vital function have been reported at high heavy metal concentration, notably silver and copper. These mechanisms can be considered as direct attack [14,39]. Mediation by heavy metals of proxy attack by free radicals also leads to protein alteration and damage [40,41].

Extensive studies have been done on the damage, inactivation and destruction of cell contents by copper applied as a biocide. Copper causes denaturing of the DNA through helical structure disorders [42]. Several DNA viruses revealed copper binding sites in every three nucleotides [43]. A covalent binding of $\mathrm{Cu}^{2+}$ has been demonstrated on DNA soaked with copper solution [44]. Multiple damage to nucleic acid is also caused by the chain of redox reaction generated by the free radicals [17]. The synergy between copper ion and the $\mathrm{H}_{2} \mathrm{O}_{2}$ oxidant has been reported to be crucial in causing multiple damage to nucleic acid. The absence of either of the two may fail to cause the damage to the DNA [45]. Gunther et al. [46] argue that copper plays a catalyst role in the 
conversion of $\mathrm{H}_{2} \mathrm{O}_{2}$ to free radicals. However, by way of resistance and within the toxicity limits, stronger competing ligands, such as glutathione and cysteine $[47,48]$, may remove copper away from the DNA in vivo. At high heavy metal concentrations, inactivation of the protein's vital formulation has been reported due to displacement of metals and interaction with the protein binding sites that lead to conformal changes to the protein structures.

\subsubsection{Complete Destruction}

Silver, under an oxygenated environment, is capable of forming reactive species and is as such known to achieve a catalytic oxidation, leading to complete inactivation of microorganisms. There is a synergy between reactive oxygen species, such as hydrogen peroxide and silver, which is assisting the inactivation process. The additive action of reactive oxygen species and silver leads to complete destruction of the cellular ingredients of microorganisms and in their loss of vitality [49]. Denaturing of the cell DNA by reactive oxygen species after the cell has been subjected to chromium is well recorded [50,51]. The reactive oxygen species, in the case of chromium, are reported to be produced through the reduction cycle of chromium undergoing change from $\mathrm{Cr}(+6)$ state to $\mathrm{Cr}$ (III) state.

Apart from destruction caused by oxidative stress involving reactive oxygen species, physiological changes within the cell structure are caused by the presence of heavy metals inside the cell. The precipitation of the protein in the cell into a condensed state is caused by the heavy metals. This physical (structural) change to DNA and protein is, in addition to the chemical reaction taking place between the heavy metal ions and complex compounds, forming the cell contents [33]. The combination of physico-chemical change taking place on the DNA and protein, results in damage, inactivation and eventually death of the microorganisms [33].

\subsubsection{Formation and Catalyzing the Action of Reactive Oxygen Species}

One process, by which reactive oxygen species, including $\mathrm{H}_{2} \mathrm{O}_{2}$, are formed, is the interaction with oxygen of the complex compounds formed by the reaction of heavy metals with the non-specific thiol groups inside the cell [24].

Heavy metals such as silver, copper and cadmium produce oxidative stressed conditions within the cell by undergoing complexation reaction with glutathione which, in turn, results in oxidation reaction with molecular oxygen and eventually the formation of reactive oxygen species. The presence of increased levels of reactive oxygen species results in an increased rate of peroxidation of lipid, damage to the DNA and process changes to the calcium and sulfhydryl homeostasis [17].

Studies surrounding the inhibitory action of chromate suggested the presence of reactive oxygen species as a result of the reduction of chromate [27-29]. The process of chromate reduction from the $\mathrm{Cr}$ (VI) to $\mathrm{Cr}$ (III) passes through $\mathrm{Cr}(\mathrm{V})$ intermediate first [52]. The process occurs cyclically and produces overall high concentration of reactive oxygen species, which will cause extensive cell damage.

The redox cycling involving $\mathrm{Cu}^{2+}$ and $\mathrm{Cu}^{1+}$ is known to generate reactive oxygen species in a manner shown by the following reactions $[17,53]$.

$$
\begin{gathered}
\mathrm{Cu}(\mathrm{II})+\mathrm{O}_{2} \bullet-\rightarrow \mathrm{Cu}(\mathrm{I})+\mathrm{O}_{2} \\
\mathrm{Cu}(\mathrm{I})+\mathrm{H}_{2} \mathrm{O}_{2} \rightarrow \mathrm{Cu}(\mathrm{II})+\cdot \mathrm{OH}^{-}+\mathrm{OH}^{-}
\end{gathered}
$$

The redox property is an important property of some of the metals that are essential to the life of cells. However, this same property, as shown above, generates toxicity to the cell. The reactive oxygen species produced as a result of such redox reactions are different forms of oxygen-based compounds which include the super oxide $\mathrm{O}_{2} \bullet$-, the hydroxyl radical $\bullet \mathrm{OH}^{-}$, and hydroxyl anion $\mathrm{OH}^{-}$. Apart from metal-induced formation, the reactive oxygen species are also formed by a number of natural sources, including oxidative phosphorylation.

\subsection{Subtle Differences and Grey Areas of the Mechanism of Destruction}

The actual mechanism of inactivation of pathogens by heavy metals is not completely known and is still the topic of active research. A considerable part of contemporary research involved observation of physiological changes to cells which is increasingly leading to better understanding of the mechanism of disinfection [33]. Of all the metals, the biocidal mechanism of action of copper has been well researched and is better understood. Much of the explanation revolves around the redox capabilities of copper [54].

There are, however, subtle differences in the types of responses to oxidative stresses as a result of the presence of different heavy metals. While the majority of the genes give a response to the stress of oxidation of dismutase, glutathione S-transferase, thioredoxin, and glutaredoxin, the individual proteins affected by the changes that followed differ from metal to metal. For example, cadmium and chromium subject different sets of glutathione S-transferase to oxidation, suggesting that there are subtle variations of the heavy metal stresses and the physiological state that follows [55].

The actual mechanism by which copper catalyses the formation of free radicals is controversial. A study on $E$. coli showed that copper did not catalyse DNA damage that caused through oxidative stresses [47]. It is argued that the majority of copper oxidative damage to the cell 
material may occur through Fenton mechanisms, particularly at high concentrations [56]. Iron-mediated oxidative damage by copper has been demonstrated [47].

The difference in biocidal properties between copper and silver, on one side, and other closely related heavy metals such as zinc and nickel, on the other, is not sufficiently explained. One argument is the ability of copper to undergo a cyclic redox reaction between $\mathrm{Cu}^{2+}$ and $\mathrm{Cu}^{+}$ that as a result, leads to damage of the cell lipid, protein and DNA while metals with close properties such as zinc and nickel do not go through such cyclic redox reactions $[8,9]$. However, zinc still possesses some biocidal properties, such as being used as an anti-fungal agent for the treatment of skin infections [10]. Zinc pyrithione is used as an anti-fouling in paints [11].

The complexity of oxidative power of heavy metals and their difference in power of oxidation is not sufficiently explained in terms of the redox potential or the redox states such as for copper and chromium. At high concentrations, for example, zinc can promote oxidative toxicity [57]. However, zinc, in ionic form, is dangerously toxic to higher organisms which limit its scope of application [12]. While it can be argued that nickel also possesses similar biocidal properties, it has a potential risk in the forms of haematotoxic, immunotoxic, neurotoxic, genotoxic, nephrotoxic, hepatotoxic and carcinogenic properties and is therefore not used extensively as biocidal agent as much as copper is [58].

\section{Materials and Methods}

$0.15 \mathrm{~g}$ of dried $E$. coli (source) was dissolved in $250 \mathrm{~mL}$ of sterile distilled water. A $0.1 \mathrm{M}$ solution of each of the 7 metal compounds was prepared using distilled water. Metal plates $0.5 \mathrm{~mm} \times 50 \mathrm{~mm} \times 50 \mathrm{~mm}$ in size were prepared. Eosin methylene blue agar was prepared and placed in a petri dish and incubated at $37^{\circ} \mathrm{C}$ for a period of 8 hours to test its sterility $0.40 \mathrm{ml}$ of the prepared $E$. coli solution was put in two separate $250 \mathrm{ml}$ glass beakers, under a running Laminar Flow Hood.

The $0.5 \mathrm{~mm} \times 50 \mathrm{~mm} \times 50 \mathrm{~mm}$ metal was immersed in one of the two glass beakers each containing $40 \mathrm{~mL}$ of $E$. coli and in the other beaker $1 \mathrm{~mL}$ of the corresponding compound was added, yielding a metal concentration of $2.5 \mathrm{mM}$. Both beakers were stirred. After every $5 \mathrm{~min}-$ utes, $1 \mathrm{~mL}$ solution from each beaker was drawn and inoculated on the sterile media plate and then spread across the plate using a spreader. The inoculated plates were incubated at $37^{\circ} \mathrm{C}$ for 48 hours. After this period, E. coli colony counts were made using a digital colony counter. The same procedure was applied for all the metal plates and corresponding compounds. Concurrent with the tests for each metal, a control blank test, without the metal or compound, was run.

\section{Results and Discussion}

The experimental data consisting of the percentage of $E$. coli colony forming units with respect to time were used to study the kinetics of inactivation of $E$. coli by the various metals and their ionic compounds employed. Figures 1 and 2 respectively show percentage of $E$. coli remaining (in percentage units) against time of disinfection by metals and their corresponding compounds. Both the metals and their ionic compounds achieved complete inactivation over a maximum period of 60 minutes. However, as can be seen from the graphs, the kinetics (rate of inactivation) varies. Most of the metals used such as copper, silver, cobalt and zinc are transition metals whose properties make them suitable for inactivation. Some of the properties of transitional metals include decreasing reactivity because of smaller ionic radius, oxidizing properties, catalytic and complex formation properties. For example, copper and silver are highly oxidizing, one of the desirable properties for disinfection. Transition metals have smaller ionic radii that increase the ionization energy and make them chemically less reactive. This property, together with the ability of transition metals to

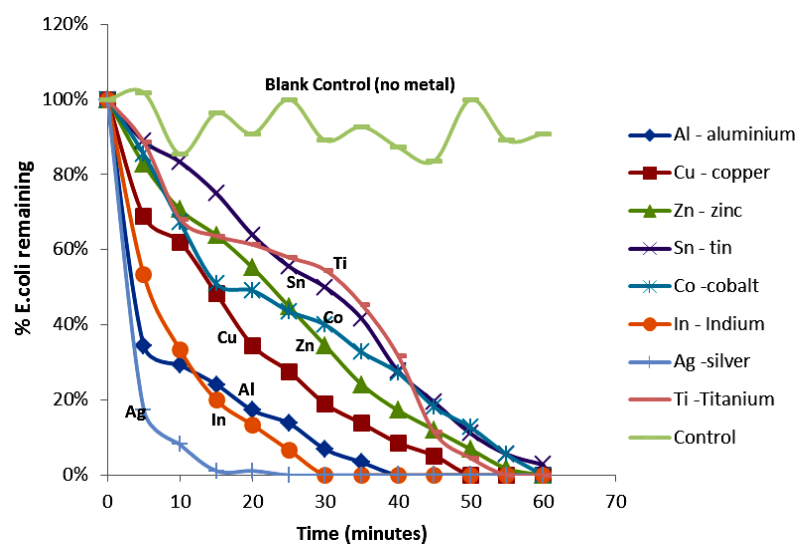

Figure 1. Percentage of $E$. coli remaining against time of inactivation by the metals.

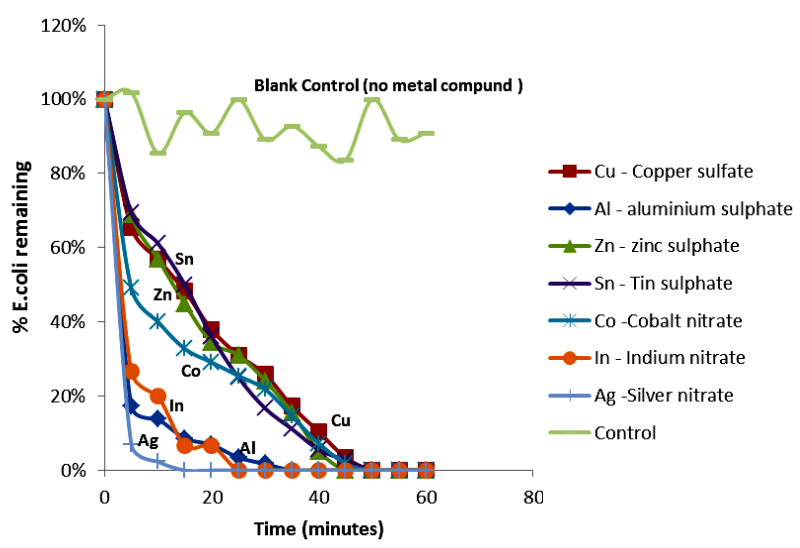

Figure 2. Percentage of $E$. coli remaining against time of inactivation by metallic compounds. 
form complex compounds, might enable them to be better available for complex formation with bacteria. Another property of the transition metals is their ability to act as catalysts for oxidation of bacteria. The catalytic properties of transition metals are achieved with their variable valence, enabling them to form unstable intermediate compounds. In other cases, the transition metals provide suitable reaction surface compounds. The case of copper undergoing $\mathrm{a}+1$ and +2 redox cycle, while acting as a catalyst for formation of reactive oxygen species has been mentioned earlier.

The order of kinetics of disinfection of the transitional metals, as shown in Figures $\mathbf{1}$ and 2, is explained by the increasing rate of inactivation as one moves from left to right across the periodic table for transition metals in the order: titanium, cobalt, zinc, copper and silver. The oxidizing property of zinc is less because the zinc group (zinc, cadmium and mercury) have low boiling and melting points (even though their ionization energy is very high) due to the low metallic bonding capabilities of the $\mathrm{s}^{2}$ electrons. While zinc is electronegative, it is readily oxidized into a stable form. Therefore, its oxidizing potential is low. In addition, zinc has a low catalytic property because the zinc structure $\left(\mathrm{d}^{10} \mathrm{~s}^{2}\right)$, indicates stability of the d-shell with 10 electrons whereas copper $\left(\mathrm{d}^{10} \mathrm{~s}^{1}\right)$ can have an oxidation state of 1 when the electron from the s shell is removed, or an oxidation state of II or even III when one or two electrons are taken from the d-shell.

Another property of the metals which is shared not only by transitional metals, but also by group three(III) metals used in the experiment (aluminum and indium), is the coagulation potential. The poor shielding of the $d-$ orbital electrons of the transitional metals increases the influence of the positive charge attraction of the nucleus thus enabling the metals to act as coagulants against negatively charged bacteria. It is also known that coagulation potential increases with increasing charge of the ion. The higher charges of aluminum and indium play a greater role for coagulation. The results of the kinetics of the inactivation experiment indicate that the group III metals (aluminum and indium) as well as their ionic equivalents achieved a faster rate of inactivation than most of the transition metals.

Both aluminum and indium display similar kinetics of inactivation, indicating that the property of inactivation is mainly influenced by the charge of +3 which is common to both ions of Group III metals in the periodic table. This property of coagulation is especially important for the metals because the electrostatic attraction of the metals can cause adsorption of bacteria onto metal surfaces thereby facilitating further inactivation by coagulation, hence making electrostatic attraction and adsorption an important mechanism for inactivation of bacteria. Colloidal silver is commonly used for inactivation of bacte- ria and coagulation is a useful property that can assist inactivation in this regard.

\subsection{Individual Metal/Ion Disinfection Kinetics Evaluation}

Figures 3 and $\mathbf{4}$ show the plots of percentage of E. coli remaining against time of inactivation for the different metals and the corresponding ionic compounds for comparison of the kinetics of inactivation of metal versus ion. Aluminum and indium, which are the Group III metals, have closer kinetics between the atoms and ions. Since both have less oxidising properties, the coagulation (adsorption) mechanism may have been similar for the atoms and ions. On the other hand, copper and silver also show similar kinetics for the atom/ion inactivation. Both copper and silver are known for their higher oxidation potential and this mechanism may have been important for both the atoms and the ions. By contrast, zinc, cobalt and tin show a significant difference in the atom versusion inactivation kinetics. The difference may be explained by the better inactivation properties of the ions through reaction and complex formation because of the low oxidation potential of these metals. These properties are not much helpful for inactivation by the metals.

\subsection{Relationship between $E$. coli Destruction and Electro-Chemical Properties of the Metals}

The variations in the rate of inactivation of the metals and metal compounds with their ionization energy, which is a measure of reactivity of the metals, are seen in Figures 5 and 6 respectively. There is a linear trend-a decrease - in the time required for inactivation with increasing ionization energy. The regression coefficient of the linear trend is 0.92 for the metals and 0.88 for the metal compounds. The greater correlation of increasing kinetics of inactivation with increasing ionization energy for the metals, in comparison with the metal compounds, might be an indication that for the metals, ions play a less important role in the inactivation of $E$. coli. Silver and titanium plot in Figure 6 as anomalies. The faster kinetics of inactivation of silver may be explained partly by the poorer shielding of the nuclear charge as the numbers of d-orbital electrons increases.

Figures 7 and 8 show the trend of inactivation of $E$. coli with respect to atomic and ionic sizes for metals and their corresponding compounds, respectively. For the metals, the trend of decreasing inactivation time with decreasing atomic size is apparent among the transition metal series involving copper, cobalt and zinc. On the other hand, the trend is weak for other metals such as aluminum, silver and indium. For the metal compounds, there is an apparent decrease in inactivation time with increasing ionic radius. However, the size of the ion may not 


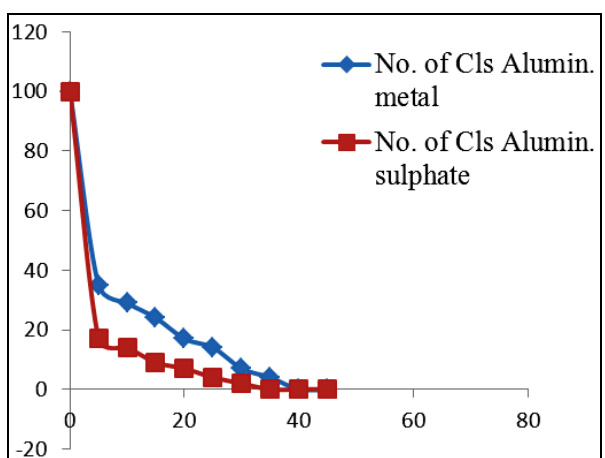

(a)

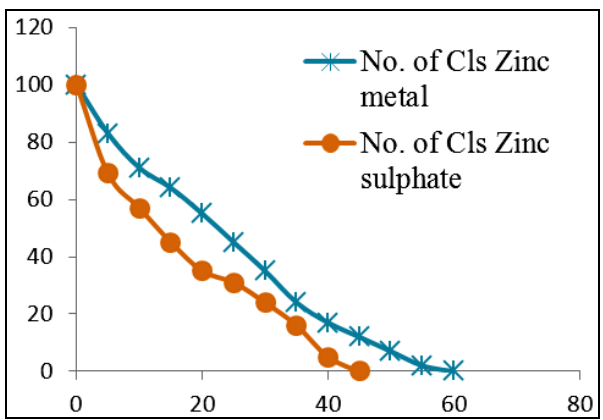

(c)

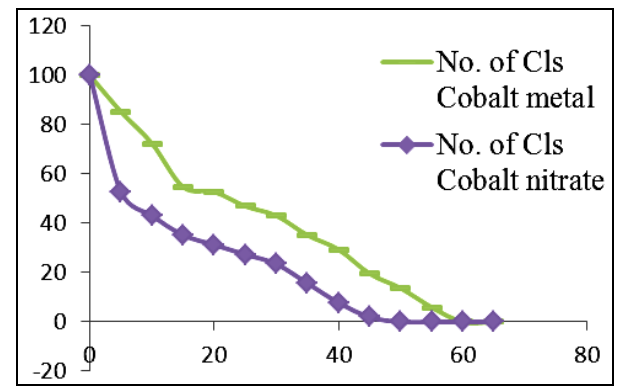

(e)

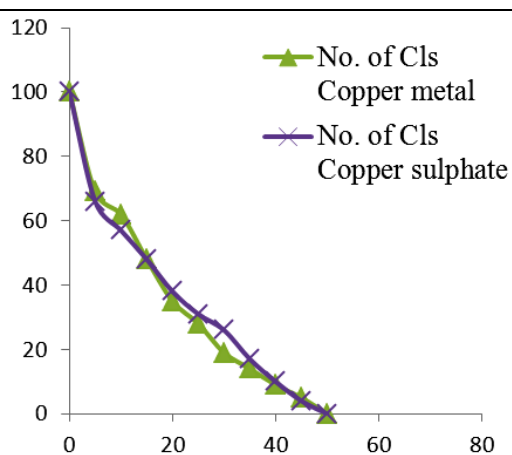

(b)

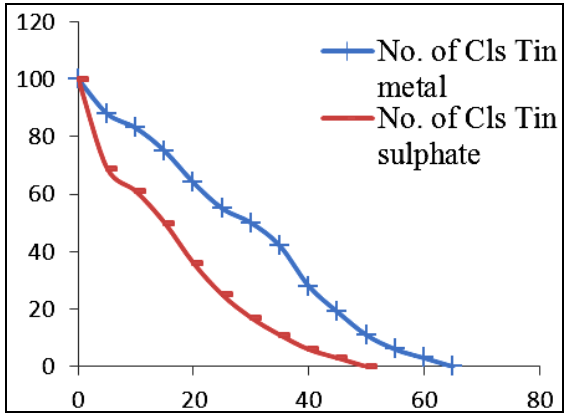

(d)

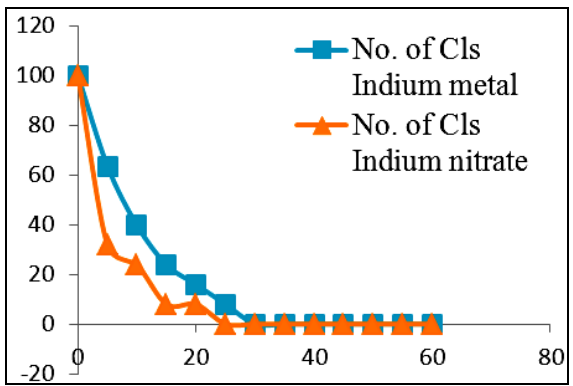

(f)

Figure 3. Percentage of $E$. coli remaining against time of inactivation for metals and their ionic counterparts ("Cls" refers to “colonies”).

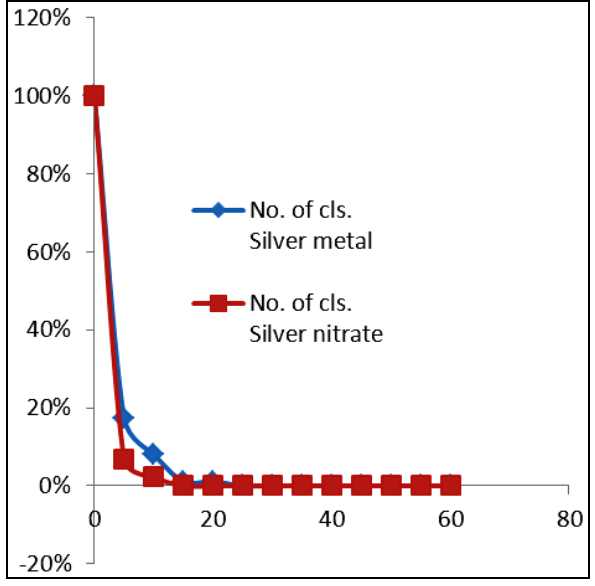

Figure 4. Percentage of $E$. coli remaining against time of inactivation for silver and its ion counterpart (“Cls” refers to “colonies”).

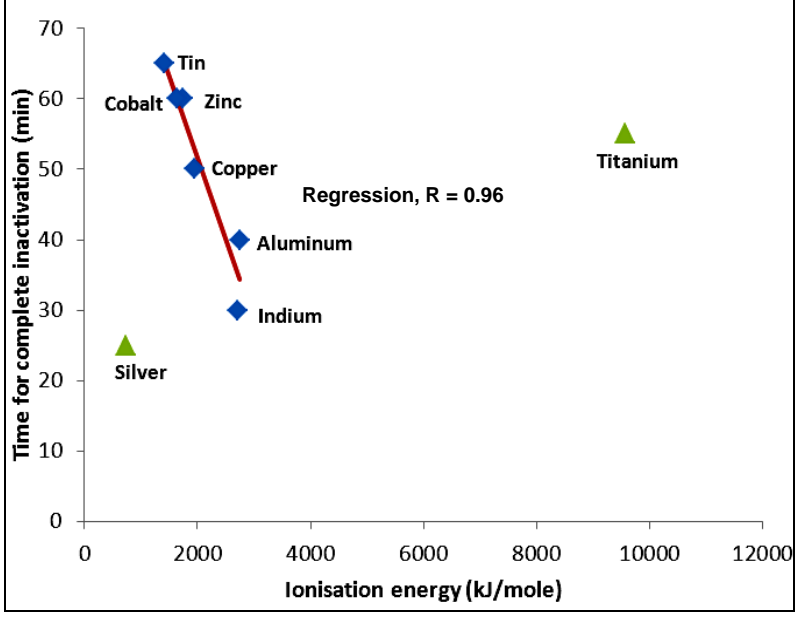

Figure 5. Variation of inactivation time by metals with ionization energy of metals. 


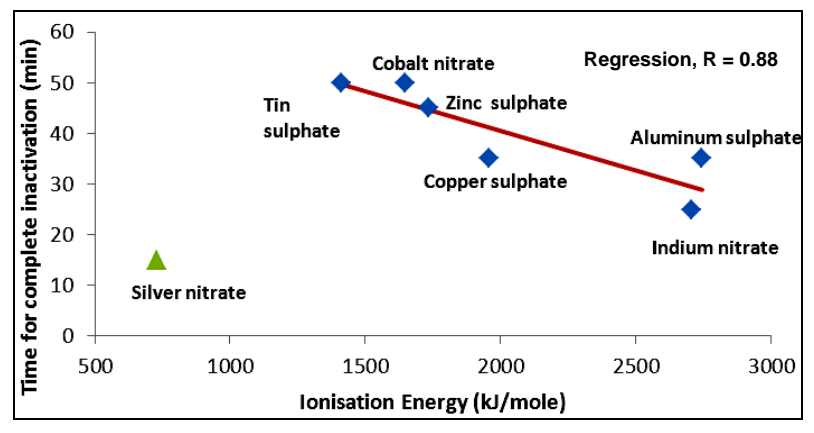

Figure 6. Variation of inactivation time by metal compounds with ionization energy of metals.

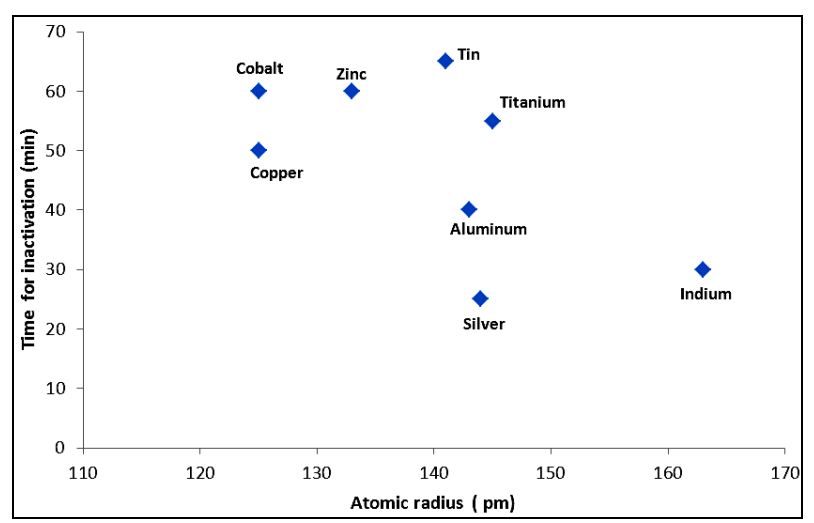

Figure 7. Variation of the time required for complete inactivation by metals with atomic radius.

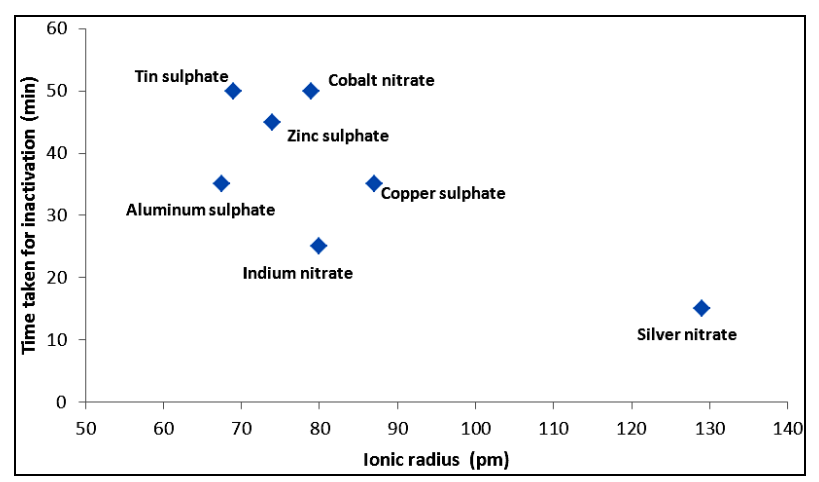

Figure 8. Variation of the time required for complete inactivation by metal compounds with ionic radius.

be the only factor explaining inactivation. For example, silver ion has a larger ionic size while its inactivation kinetics is fast, partly due to the poor shielding of the nuclear charge by the d-orbital electrons. The trend of faster kinetics of inactivation might thus be more appropriately linked to increasing nuclear charge. However, the combination of increasing nuclear charge and the comparatively smaller ionic radii of transition metals still play a role in the inactivation kinetics along with other properties of the metals, such as higher oxidation potential, complex forming ability, coagulation and catalytic action. These are also related to the presence of easily transferable $d$ orbital electrons and due to poor shielding of the d orbitals as the atomic number increases particularly for the transition metals.

As explained in the preceding sections, heavy metals generally react with proteins by combining with the thiol groups that leads to the inactivation of the proteins. The concentration of heavy metals used in the tests $(2.5 \mathrm{mM})$ may be high enough to cause membrane destruction and protein denaturing. The data obtained in terms of the time taken to achieve complete destruction of E. coli for a number of metals has been compared with the free energy of formation of metal sulphides. Table 1 below shows the solubility and free energy of formation of sulphides for a number of metals.

A plot of the time taken to achieve complete inactivation of $E$. coli was plotted against the free energy of formation of metal sulphides according to the data of Table 1. Figure 9 shows the result of such a plot. It is clear that, generally, the time taken to achieve disinfection falls. As expected, ions achieve faster inactivation than atoms. However, for the metals with lower free energy of formation (copper and silver) the difference between atom and ion inactivation is considerably small compared with metals of higher energy of formation. This partly indicates the relative significance of formation of reactive oxygen species compared to direct ionic oxidation of metals, leading to DNA denaturing which is facilitated through ion formation. On the other hand, atoms with higher free energy of formation show a significant dif-

Table 1. Comparison of free energy of formation of metal sulphides with time taken to achieve complete inactivation.

\begin{tabular}{ccccc}
\hline Compound & $\mathbf{K}_{\text {sp }}$ & $\begin{array}{c}\Delta \mathbf{F f}^{\mathbf{0}} \\
\text { (joules) }\end{array}$ & $\begin{array}{c}\text { Time taken to } \\
\text { inactivate for } \\
\text { compound (min) }\end{array}$ & $\begin{array}{c}\text { Time taken to } \\
\text { inactivate for } \\
\text { metals (min) }\end{array}$ \\
\hline $\mathrm{Ag}_{2} \mathrm{~S}$ & $6.7 \times 10^{-50}$ & -9.3 & 15 & 25 \\
$\mathrm{CuS}$ & $6.3 \times 10^{-36}$ & -11.7 & 35 & 50 \\
$\mathrm{CoS}$ & $2.0 \times 10^{-25}$ & -19.8 & 50 & 60 \\
$\mathrm{ZnS}$ & $1.6 \times 10^{-23}$ & -47.4 & 45 & 60 \\
\hline
\end{tabular}

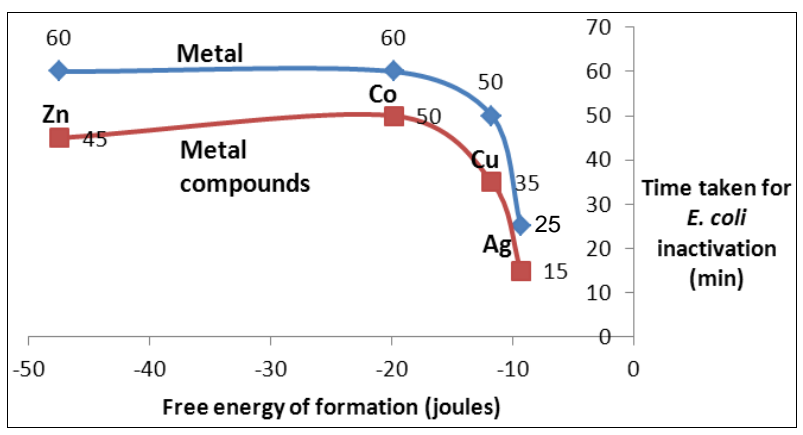

Figure 9. Variation of inactivation time with free energy of formation of heavy metals and metal compounds. 
ference in the rate of inactivation between atoms and ions. The difference is expected to get wider when a lower concentration of metals is used as is normally the case with potable water disinfection with metals. On the other hand, it is noticed from Figure 9 shows that the time required for complete inactivation of $E$. coli falls much faster at low free energy of formation. Therefore, although cobalt and copper have a significant difference in energy of formation, the time required for inactivation does not vary much. The opposite is true for copper and silver. Both of these have low free energy of formation with a small difference in values (Table 1). However, the time required for inactivation with silver is much smaller than that of copper. This is a result of the increase in the number of protons in the silver ions compared to copper while the increased number of electrons is filled in the dorbitals with poor shielding of the protons' attraction potential.

\subsection{Evaluation of Inactivation Kinetics with Respect to Reduction-Oxidation Properties Metals}

Table 2 shows the standard redox potentials of the metals for $E$. coli in activation. The potentials are given with respect to reduction of a hydrogen ion to a hydrogen gas and show the relative potentials of the metals in reduction.

The high oxidation potential of silver and copper compared to the other metals. On the other hand, metals on the lower part of the table have limited oxidation potential as they are oxidized in turn. Zinc belongs to this set.

In order to examine the relationship between the kinetics of inactivation with the redox activity of the metals which potentially influences the production of reactive oxygen species that have oxidative power, the time taken for complete inactivation of $E$. coli is tabulated against standard redox potential of the metals as shown in Table 2.

Figure 10 shows a plot of the time taken for complete inactivation of $E$. coli against standard redox potential for the metals used in the experiments. As expected, the kinetics is considerably faster for the atoms with higher oxidation potential, such as copper and silver. By contrast, for zinc, aluminum and titanium, the oxidation potential does not show a meaningful trend with the redox potential. This observation is in line with previous observations that metals, such as zinc, show stability and do not undergo redox cycling [12].

In fact, the metals aluminum and indium show an anomaly with respect to redox potential indicating that the inactivation kinetics is not explained solely by oxidation potential. Other factors such as coagulation should be taken into consideration.
Table 2. Redox potentials and time taken for complete inactivation.

\begin{tabular}{ccccc}
\hline Atom & Symbol & $\begin{array}{c}\text { Redox } \\
\text { potential } \\
(\mathbf{m V})\end{array}$ & $\begin{array}{c}\text { Time taken to } \\
\text { inactivate for } \\
\text { compounds (min) }\end{array}$ & $\begin{array}{c}\text { Time taken to } \\
\text { inactivate for } \\
\text { metals (min) }\end{array}$ \\
\hline Silver & $\mathrm{Ag}$ & 0.8 & 15 & 25 \\
Copper & $\mathrm{Cu}$ & 0.34 & 35 & 50 \\
Tin & $\mathrm{Sn}$ & -0.14 & 50 & 65 \\
Cobalt & $\mathrm{Co}$ & -0.28 & 50 & 60 \\
Indium & $\mathrm{In}$ & -0.34 & 25 & 30 \\
Zinc & $\mathrm{Zn}$ & -0.76 & 45 & 60 \\
Titanium & $\mathrm{Ti}$ & -1.63 & $\mathrm{NA}^{*}$ & 60 \\
Aluminum & $\mathrm{Al}$ & -1.66 & 35 & 40 \\
\hline
\end{tabular}

*The metal compound for titanium was not available.

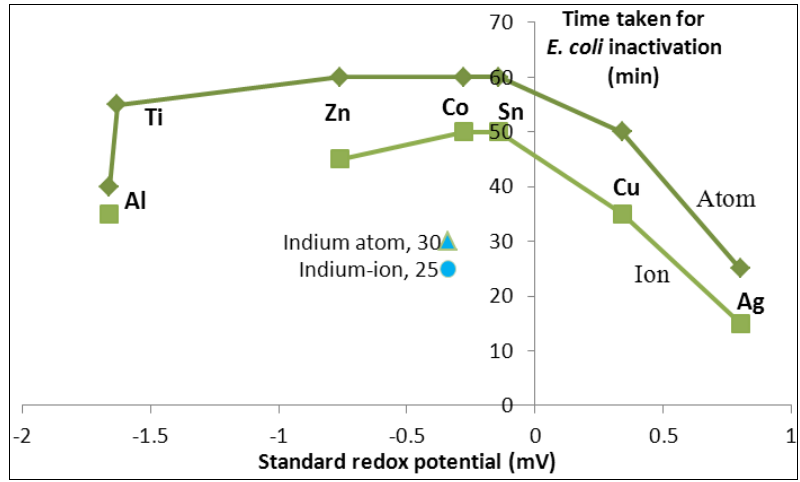

Figure 10. Variation of inactivation time with redox potential of heavy metals.

\section{Conclusions}

The rate of inactivation showed variation among the different metals and metal compounds. The rate of inactivation for several of the transition metals as well as the Group III metals (aluminum and indium) showed a decreasing linear relationship with their respective ionization energies. For the transition metals, the rate of inactivation increases as one moves to the right along the row of the transition series with the well-known property that the ionic radii of the metals increase while doing so. In addition, non-transition, Group III metals, such as aluminum and indium show faster inactivation comparable to that of silver due probably to the increase in coagulation potential and the resulting adsorption of bacteria as a result of the larger charge carried by these atoms.

The experimental results showed that for the metals, adsorption through coagulation seems to be the most important factor. Future experiments with metals aimed at enhancing such a mechanism of inactivation might yield a greater rate of inactivation than what is being realized at present. For the metal compounds, additional mecha- 
nisms, such as direct reaction through complex formation, physico-chemical distortion of the cells' vital contents through direct entry of the ions into the cell structure may contribute towards greater inactivation. These factors are made evident through the association of the rate of inactivation with redox potential and free energy of formation of the metals with the sulfide groups. There is, in general, a difference between the metals and metal compounds in terms of their rate of inactivation. This difference is larger for the transition metals that have lower oxidation potential, higher ionization energy as well as larger ionic radii.

The results also showed that the rate of inactivation for the metals and metal compounds follow a trend with the free energy of formation with sulfide, with the metals having properties that enable them to form complexes with SH groups within the cell as well as the redox potential that enables the metals to catalyze the formation of the cell-destroying reactive oxygen species. Metals such as copper and silver, with higher oxidation potential and higher free energy of formation, show a faster rate of inactivation of $E$. coli. By contrast, the rate of inactivation of $E$. coli by metals with low redox potential and free energy of formation with the sulfide groups is generally poor. The results point to a possible future work with the active metals to increase their coagulation, reactive and oxidation potential, with a view to enhancing the inactivation of pathogens and increasing the scope of application of heavy metals for disinfection purposes.

\section{REFERENCES}

[1] R. C. Weast, "CRC Handbook of Chemistry and Physics,” 64th Edition, CRC Press, Boca Raton, 1984.

[2] D. H. Nies, “Microbial Heavy-Metal Resistance,” Applied Microbiology and Biotechnology, Vol. 51, No. 6, 1999, pp. 730-750. http://dx.doi.org/10.1007/s002530051457

[3] M. Valls and V. de Lorenzo, "Exploiting the Genetic and Biochemical Capacities of Bacteria for the Remediation of Heavy Metal Pollution,” FEMS Microbiological Reviews, Vol. 26, No. 4, 2002, pp. 327-338.

[4] D. L. Godbold and A. Hüttermann, "Effect of Zinc, Cadmium and Mercury on Root Elongation of Piceaabies (Karst.) Seedlings, and the Significance of These Metals to Forest Die-Back," Environmental Pollution, Vol. 38, No. 4, 1985, pp. 375-381. http://dx.doi.org/10.1016/0143-1471(85)90108-4

[5] C. W. Breckle, “Growth under Heavy Metals," In: Y. Waisel, A. Eshel and U. Kafkafi, Eds., Plant Roots: The Hidden Half, Marcel Dekker, New York, 1991, pp. 351373.

[6] T. J. Berger, J. A. Sparado, S. E. Chapin and R. O. Becker, "Electrically Generated Silver Ions: Quantitative Effects on Bacterial and Mammalian Cells,” Anti Microb. Agents, 1996, pp. 357-358.

[7] J. J. Hostynek and H. I. Maibach, "Hypersensitivity: Der- matologic Aspects-An Overview,” Reviews on Environmental Health, Vol. 153, No. 3, 2003, pp. 153-183.

[8] G. Borkow and J. Gabbay, “Copper as a Biocidal Tool," Current Medicinal Chemistry, Vol. 12, No. 18, 2005, pp. 2163-2175. http://dx.doi.org/10.2174/0929867054637617

[9] M. Valko, H. Morris and M. T. Cronin, "Metals, Toxicity and Oxidative Stress," Current Medicinal Chemistry, Vol. 12, No. 10, 2005, pp. 1161-1208. http://dx.doi.org/10.2174/0929867053764635

[10] H. Rieth, "Killing of Pathogenic Fungi with Organic Zinc Compounds. Fungicidal Aerosol Disinfection and Accumulative Impregnation,” Mykosen, Vol. 11, No. 9, 1968, pp. 667-670. http://dx.doi.org/10.1111/j.1439-0507.1968.tb03410.x

[11] I. K. Konstantinou and A. T Albanis, "Worldwide Occurrence and Effects of Antifouling Paint Booster Biocides in the Aquatic Environment: A Review,” Environment International, Vol. 30, No. 2, 2004, pp. 235-248. http://dx.doi.org/10.1016/S0160-4120(03)00176-4

[12] R. Eisler, "Zinc Hazard to Fish, Wildlife, and Invertebrates: A Synoptic Review,” Contaminant Hazard Reviews, US Department of the Interior, Fish and Wildlife Service, Laurel, 1993.

http://www.pwrc.usgs.gov/infobase/eisler/chr_26_zinc.pd $\mathrm{f}$

[13] J. H. Kim, H. Cho, S. E. Ryu and M. U. Choi, "Effects of Metal Ions on the Activity of Protein Tyrosine Phosphatase VHR: Highly Potent and Reversible Oxidative Inactivation by Cu2+ Ion," Archives of Biochemistry and Biophysics, Vol. 382, No. 1, 2000, pp. 72-80. http://dx.doi.org/10.1006/abbi.2000.1996

[14] A. R. Karlstrom and R. L. Levine, "Copper Inhibits the Protease from Human Immunodeficiency Virus 1 by Both Cysteine-Dependent and Cysteine-Independent Mechanisms," Proceedings of the National Academy of Sciences, Vol. 88, No. 13, 1991, pp. 5552-5556.

http://dx.doi.org/10.1073/pnas.88.13.5552

[15] C. Cervantes and F. Gutierrez-Corona, "Copper Resistance Mechanisms in Bacteria and Fungi," FEMS Microbiology Reviews, Vol. 14, No. 2, 1994, pp. 121-137.

[16] Y. Ohsumi, K. Kitamoto and Y. Anraku, "Changes Induced in the Permeability Barrier of the Yeast Plasma Membrane by Cupric Ion,” Journal of Bacteriology, Vol. 170, No. 6, 1988, pp. 2676-2682.

[17] S. K. Stosh and D. Bagchi, "Oxidative Mechanisms in the Toxicity of Metal Ions,” Free Radical Biology \& Medicine, Vol. 18, No. 2, 1995, pp. 321-336. http://dx.doi.org/10.1016/0891-5849(94)00159-H

[18] P. R. Blackett, D. M. Lee, D. L. Donaldson, J. D. Fesmire, W. Y. Chan, J. H. Holcombe and O. M. Rennert, "Studies of Lipids, Lipoproteins, and Apolipoproteins in Menkes' Disease," Pediatric Research, Vol. 18, No. 9, 1984, pp. 864-870. http://dx.doi.org/10.1203/00006450-198409000-00012

[19] A. H. Ding and P. C. Chan, "Singlet Oxygen in CopperCatalyzed Lipid Peroxidation in Erythrocyte Membranes,” Lipids, Vol. 19, No. 4, 1984, pp. 278-284.

[20] P. C. Chan, O. G. Peller and L. Kesner, “Copper (II)-Ca- 
talyzed Lipid Peroxidation in Liposomes and Erythrocyte Membrane,” Lipids, Vol. 17, No. 5, 1982, pp. 331-337.

[21] J. R. Hazel and E. E. Williams, “The Role of Alterations in Membrane Lipid Composition in Enabling Physiological Adaptation of Organisms to Their Physical Environment," Progress in Lipid Research, Vol. 29, No. 3, 1990, pp. 167-227. http://dx.doi.org/10.1016/0163-7827(90)90002-3

[22] S. V. Avery, J. L. Harwood and D. Lloyd, "Quantification and Characterization of Phagocytosis in the Soil Amoeba Acanthamoebacastellanii by Flow Cytometry," Applied and Environmental Microbiology, Vol. 61, No. 3, 1995, pp. 1124-1132.

[23] H. Elzanowska, R. G. Wolcott, D. M. Hannum and J. K. Hurst, "Bactericidal Properties of Hydrogen Peroxide and Copper or Iron-Containing Complex Ions in Relation to Leukocyte Function,” Free Radical Biology \& Medicine, Vol. 18, No. 3, 1995, pp. 437-449.

[24] A. V. Kachur, C. J. Koch and J. E. Biaglow, "Mechanism of Copper-Catalyzed Oxidation of Glutathione," Free Radical Research, Vol. 28, No. 3, 1998, pp. 259-269. http://dx.doi.org/10.3109/10715769809069278

[25] D. H. Nies and N. Brown, "Two-Component Systems in the Regulation of Heavy Metal Resistance,” In: S. Silver and W. Walden, Eds., Metal Ions in Gene Regulation, Chapman and Hall, London and New York, 1998, pp. 77103. http://dx.doi.org/10.1007/978-1-4615-5993-1_4

[26] P. Gong, O. Y. Ogra and S. Koizumi, "Inhibitory Effects of Heavy Metals on Transcription Factor Sp1,” Industrial Health, Vol. 38, No. 2, 2000, pp. 224-227. http://dx.doi.org/10.2486/indhealth.38.224

[27] C. Cervantes, J. Campos-Garcia, S. Devars, F. GutierrezCorona, H. Loza-Tavera, J. C. Torres-Guzman and R. Moreno-Sanchez, "Interactions of Chromium with Microorganisms and Plants," FEMS Microbiology Reviews, Vol. 25, No. 3, 2001, pp. 335-347. http://dx.doi.org/10.1111/j.1574-6976.2001.tb00581.x

[28] J. D. L. Singh, Carlisle, D. E. Pritchard and S. R. Patierno, "Chromium-Induced Genotoxicity and Apoptosis: Relationship to Chromium Carcinogenesis,” Oncology Reports, Vol. 5, No. 6, 1998, 1307-1318.

[29] Y. Suzuki, T. Sato, H. Isobe, T. Kogure and T. Murakami, "Dehydration Processes of the Meta-Autunite Group Minerals, Meta-Autunite, Metasaléeite and Metatorbernite,” American Mineralogist, Vol. 70, No. 8-9, 2005, pp. 13081314. http://dx.doi.org/10.2138/am.2005.1568

[30] L. Nan, Y. Liu, M. Lu and K. Yang, "Study on Antibacterial Mechanism of Copper-Bearing Austenitic Antibacterial Stainless Steel by Atomic Force Microscopy," Journal of Materials Science: Materials in Medicine, Vol. 19, No. 9, 2008, pp. 3057-3062. http://dx.doi.org/10.1007/s10856-008-3444-z

[31] S. V. Avery, N. G. Howlett and S. Radice, “Copper Toxicity towards Saccharomyces Cerevisiae: Dependence on Plasma Membrane Fatty Acid Composition,” Applied and Environmental Microbiology, Vol. 62, No. 11, 1996, pp. 3960-3966.

[32] M. Mergeay, D. Nies, H. G. Schlrgrl, J. Gerits and P. Charles, "Alcaligeneseutorophus CH34 Is a Facultative
Chemolithotroph with Plasmid-Bound Resistance to Heavy Metals," Journal of Bacteriology, Vol. 162, No. 1, 1985, pp. 328-334.

[33] Q. K. Feng, J. Wu, G. Q. Chen, F. Z. Cui, T. N. Kim and J. O. Kim, "A Mechanistic Study of the Antibacterial Effect of Silver Ions on Escherichia coli and Staphylococcus Aureus," Journal of Biomedical Materials Research, Vol. 52, No. 4, 2000, pp. 662-668.

[34] C. Rensing, B. Mitra and B. P. Rosen, "Insertional Inactivation of dsbA Produces Sensitivity to Cadmium and Zinc in Escherichia coli," Journal of Bacteriology, Vol. 179, No. 8, 1997, pp. 2769-2771.

[35] A. L. Lehninger, D. L. Nelson and M. M. Cox, "Principles of Biochemistry,” 2nd Edition, New York, 1993.

[36] S. Y. Liau, D. C. Read, W. J. Pugh, J. R. Furr and A. D. Russell, "Interaction of Silver-Nitrate with Readily Identifiable Groups: Relationship to the Anti-Bacterial Action of Silver Ions,” Letters in Applied Microbiology, Vol. 25, No. 4, 1997, pp. 279-283.

http://dx.doi.org/10.1046/j.1472-765X.1997.00219.x

[37] F. Hussain, E. Sedlak and P. Wittung-Stafshede, "Role of Copper in Folding and Stability of Cupredoxin-Like Copper-Carrier Protein CopC,” Archives of Biochemistry and Biophysics, Vol. 467, No. 1, 2007, pp. 58-66. http://dx.doi.org/10.1016/j.abb.2007.08.014

[38] F. Hussain and P. Wittung-Stafshede, "Impact of Cofactor on Stability of Bacterial (CopZ) and Human (Atox1) Copper Chaperones,” Biochimica et Biophysica Acta, Vol. 1774, No. 10, 2007, pp. 1316-1322. http://dx.doi.org/10.1016/j.bbapap.2007.07.020

[39] A. R. Karlstrom, B. D. Shames and R. L. Levine, "Reactivity of Cysteine Residues in the Protease from Human Immunodeficiency Virus: Identification of a Surface-Exposed Region Which Affects Enzyme Function,” Archives of Biochemistry and Biophysics, Vol. 304, No. 1, 1993, pp. 163-169. http://dx.doi.org/10.1006/abbi.1993.1334

[40] M. J. Davies, B. C. Gilbert and R. M. Haywood, "Radical-Induced Damage to Proteins: E.S.R. Spin-Trapping Studies," Free Radical Research, Vol. 15, No. 2, 1991, pp. 111-127. http://dx.doi.org/10.3109/10715769109049131

[41] R. T. Dean, S. P. Wolff and M. A. McElligott, "Histidine and Proline are Important Sites of Free Radical Damage to Proteins,” Free Radical Research, Vol. 7, No. 2, 1989, pp. 97-103.

http://dx.doi.org/10.3109/10715768909087929

[42] R. B. Martin and Y. H. Mariam, "Metal Ions in Solution," Marcel Dekker, Basel, 2001.

[43] K. L. Sagripanti, M. L. Swicord and C. C. Davis, "Microwave Effects on Plasmid DNA,” Radiation Research, Vol. 110, No. 2, 1987, pp. 219-231.

[44] B. H. Geierstanger, T. F. Kagawa, S. L. Chen, G. J. Quigley and P. S. Ho, "Basespecific Binding of Copper (II) to Z-DNA. The 1.3-A Single Crystal Structure of d(m5CGUAm5CG) in the Presence of CuCl2," The Journal of Biological Chemistry, Vol. 266, No. 30, 1991, pp. 20185-20191.

[45] E. Keyhani, F. Abdi-Oskouei, F. Attar and J. Keyhani, "DNA Strand Breaks by Metal-Induced Oxygen Radicals 
in Purified Salmonella Typhimurium DNA,” Annals of the New York Academy of Sciences, Vol. 1091, No. 1, 2006, pp. 52-64.

http://dx.doi.org/10.1196/annals.1378.054

[46] M. R. Gunther, P. M. Hanna, R. P. Mason and M. S. Cohen, "Hydroxyl Radical Formation from Cuprous Ion and Hydrogen Peroxide: A Spin-Trapping Study,” Archives of Biochemistry and Biophysics, Vol. 316, No. 1, 1995, pp. 515-522. http://dx.doi.org/10.1006/abbi.1995.1068

[47] L. Macomber, C. Rensing and J. A. Imlay, "Intracellular Copper does not Catalyze the Formation of Oxidative DNA Damage in Escherichia coli," Journal of Bacteriology, Vol. 189, No. 5, 2007, pp. 1616-1626. http://dx.doi.org/10.1128/JB.01357-06

[48] A. Schrammel, D. Koesling, A. C. Gorren, M. Chevion, K. Schmidt and B. Mayer, "Inhibition of Purified Soluble Guanylyl Cyclase by Copper Ions,” Biochemical Pharmacology, Vol. 52, No. 7, 1996, pp. 1041-1045. http://dx.doi.org/10.1016/0006-2952(96)00425-X

[49] R. Pedahzur, H. L. Shuval and S. Ulitzur, "Silver and Hydrogen Peroxide as Potential Drinking Water Disinfectants: Their Bactericidal Effects and Possible Modes of Action," Water Science and Technology, Vol. 35, No. 11-12, 1997, pp. 87-93. http://dx.doi.org/10.1016/S0273-1223(97)00240-0

[50] J. Aiyar, H. J. Berkovits, R. A. Floyd and K. E. Wetterhahn, "Reaction of Chromium (VI) with Hydrogen Peroxide in the Presence of Glutathione: Reactive Intermediates and Resulting DNA Damage,” Chemical Research Toxicology, Vol. 3, No. 6, 1990, pp. 595-603. http://dx.doi.org/10.1021/tx00018a016

[51] K. E. Wetterhahn, J. W. Hamilton, J. Aiyar, K. M. Borges and R. Floyd, "Mechanisms of Chromium(VI) Carcinogenesis. Reactive Intermediates and Effect on Gene Expression,” Biological Trace Element Research, Vol. 21, No. 1, 1989, pp. 405-411.

http://dx.doi.org/10.1007/BF02917282
[52] M. A. S. Fernandez, M. S. Santos, M. C. Alpoim, V. M. C. Madeira and J. A. F. Vicente, "Chromium (VI) Interaction with Plant and Animal Mitochondrial Bioenergetics: A Comparative Study,” Journal of Biochemical and Molecular Toxicology, Vol. 16, No. 2, 2002, pp. 53-63. http://dx.doi.org/10.1002/jbt.10025

[53] C. Barata, S. J. Markich, D. J. Baird, G. Taylor and A. M. V. M. Soares, "Genetic Variability in Sub Lethal Tolerance to Mixtures of Cadmium and Zinc in Clones of Daphnia magna Straus,” Aquatic Toxicology, Vol. 60, No. 1-2, 2002, pp. 85-99. http://dx.doi.org/10.1016/S0166-445X(01)00275-2

[54] K. Apel and H. Hirt, "Reactive Oxygen Species: Metabolism, Oxidative Stress, and Signal Transduction,” Annual Review of Plant Biology, Vol. 55, No. 1, 2004, pp. 373399. http://dx.doi.org/10.1146/annurev.arplant.55.031903. 141701

[55] P. Hu, E. L. Brodie, Y. Suzuki, H. H. McAdams and G. L. Andersen, "Whole-Genome Transcriptional Analysis of Heavy Metal Stresses in Caulobactercrescentus,” Journal of Bacteriology, Vol. 187, No. 24, 2005, pp. 8437-8449.

[56] C. Manzl, J. Enrich, H. Ebner, R. Dallinger and G. Krumschnabel, "Copper-Induced Formation of Reactive Oxygen Species Causes Cell Death and Disruption of Calcium Homeostasis in Trout Hepatocytes," Toxicology, Vol. 196, No. 1-2, 2004, pp. 57-64. http://dx.doi.org/10.1016/j.tox.2003.11.001

[57] R. O. Wright and A. Baccarelli, "Metals and Neurotoxicology,” The Journal of Nutrition, Vol. 137, No. 12, 2007, pp. 2809-2813.

[58] K. K. Das, S. N. Das and S. A. Dhundasi, "Nickel, Its Adverse Health Effects \& Oxidative Stress," The Indian Journal of Medical Research, Vol. 128, No. 4, 2008, pp. 412-425. 